\title{
LETTERS
}

\section{Gun control: a health issue, a legal issue or both}

I have followed the gun control debate in the United States for a couple of years and am now following the current confrontation between physicians and gun lobbyists here in Canada. All those who have been debating this issue are in agreement in their wish to prevent gunshot injuries. No one is pro-gunshot injuries.

Those trying to demonize groups who disagree with them do the debate itself a great disservice. Except for some fanatics, everyone would agree that weaponizing the College of Physicians and Surgeons of Ontario against Canadian Doctors for Protection from Guns was inappropriate and wrong.
By the same token, the inflammatory comment in Dr. Stanbrook's editorial that "the gun lobby has been good at hindering both production and discourse of evidence linking guns and health," 1 serves to lower the discourse of the gun control debate, making logical discussion and ultimate agreement on some solutions less likely. I agree that "[n]o one should be marginalized or silenced from engaging in reasonable debate about where the line should best be drawn between public health and safety and individual choices," and that should also include those who disagree with the solutions proposed by Canadian Doctors for Protection from Guns.

Some physicians are experts on the effects of gunshots on the human body and their treatment. There is nothing intrinsic in physician experience or training that makes physicians experts on gun control policy. Canadian Doctors for Protection from Guns may or may not be absolutely correct in its goals and methodology, but it makes sense to me that a big part of the solution would be enforcing the laws that are already in place.

\section{Gerald I. Goldlist MD}

Ophthalmologist (retired), Markham, Ont.

Cite as: CMAJ 2019 August 26;191:E948. doi: $10.1503 / \mathrm{cmaj} .72602$

\section{Reference}

1. Stanbrook M. Gun control: a health issue for which physicians rightfully advocate [editorial]. CMAJ 2019;191:E434-5.

Competing interests: None declared. 